\title{
Sistem Monitoring Server Dengan Menggunakan SNMP
}

\author{
Alehandrew Michael ${ }^{1, *}$, Hendi Hermawan ${ }^{2, *}$, Heny Ispur Pratiwi ${ }^{3}$ \\ ${ }^{1}$ Program Studi Informatika, Universitas Pembangunan Jaya \\ alehandrewmichael@gmail.com \\ ${ }^{2}$ Program Studi Informatika, Universitas Pembangunan Jaya \\ hendi.hermawan@upj.ac.id \\ ${ }^{3}$ Program Studi Informatika, Universitas Pembangunan Jaya \\ heny.pratiwi@upj.ac.id
}

Received 31 August 2019, Revised 14 September 2019, Accepted 23 September 2019

\begin{abstract}
Servers are the main components in a computer networks system to provide services to the users or commonly known as the clients. The activities and operational services of a server to the client include many processes to fulfill the client requests sent to the server. A system to monitor all activities in the server is needed such that the administrator (operator) can monitor and detect if any problem occurs on the server. This system also applies server service livelihood automation for a server that is experiencing suddenly dead conditions. Programming languages used in building this system are python, php, and shell script. The reason of using Python is due to superior capabilities in connecting the Simple Network Management Protocol (SNMP). The SNMP is a network management protocol that regulates and stores all network information in it. The system is implemented by a web that provides information about the monitored server.
\end{abstract}

Keywords: Server, SNMP, Python, PHP, Shell Script

\begin{abstract}
Abstrak - Server merupakan komponen utama sistem jaringan komputer yang berfungsi untuk menyediakan suatu layanan kepada pengguna yang biasa disebut sebagai client. Aktifitas dan operasional pelayanan sebuah server terhadap client dalam penerapannya terdiri dari begitu banyak proses untuk memenuhi segala permintaan client yang dikirimkan pada server tersebut. Diperlukan suatu sistem yang mampu melakukan pemantauan segala aktivitas di dalam server sehingga administrator (operator) bisa memonitor dan mendeteksi apabila terjadi permasalahan pada server yang digunakan. Sistem ini juga menerapkan otomatisasi penghidupan layanan server terhadap layanan server yang mengalami kondisi mati secara tiba-tiba. Bahasa pemrograman yang digunakan untuk membangun sistem ini adalah python, php, dan shell script. Alasan menggunakan bahasa pemrograman python pada sistem ini adalah memiliki kemampuan yang unggul dalam melakukan koneksi protokol SNMP (Simple Network Management Protocol). Hal ini dikarenakan protokol SNMP merupakan protokol manajemen jaringan yang mengatur dan menyimpan segala informasi jaringan di dalamnya. Hasil luaran dari sistem ini adalah sebuah web yang mampu mengeluarkan beberapa informasi mengenai server yang dipantau.
\end{abstract}

Kata Kunci: Server, SNMP, Python, PHP, Shell Script

\section{PENDAHULUAN}

Server adalah sebuah sistem komputer yang terdapat pada jaringan komputer untuk menyediakan suatu layanan kepada pengguna yang disebut sebagai client. Dibalik penggunaannya, server telah melakukan banyak proses untuk memenuhi permintaan dari client, oleh sebab itu sering kali server mengalami gangguan yang dikarenakan server tidak memiliki sumber daya (resource) yang mumpuni untuk memenuhi kebutuhan tersebut. Hal ini menyebabkan layanan server mati secara tiba-tiba dikarenakan kernel memutuskan untuk non-aktifkan layanan server yang membutuhkan resource yang besar. Kernel adalah komponen inti dari sistem operasi. Kernel bertanggung jawab untuk mengerjakan tugas-tugas tingkat rendah seperti manajemen disk, manajemen tugas dan manajemen memori.

Permasalahan ini dapat teratasi dengan membangun sistem pemantauan server yang mampu mengumpulkan beberapa informasi server seperti IS (information system), informasi sumber daya sistem (resource), dan informasi ethernet interface. Kebutuhan yang diperlukan dalam membangun sistem ini adalah protokol SNMP (Simple Network Management Protocol) yang merupakan suatu protokol yang digunakan untuk mengolah dan memonitor perangkat jaringan. SNMP menggunakan sistem log yang menyimpan segala informasi dari perangkat jaringan yang terdaftar. Sehingga keuntungan dari menggunakan SNMP dapat mengambil segala kebutuhan informasi perangkat 
yang digunakan dan dapat ditampilkan untuk memenuhi kebutuhan sistem monitoring.

Penelitian ini bertujuan untuk menghasilkan sebuah aplikasi monitoring server berbasis web agar mendukung pemantauan server secara remote. Selain itu web dapat diakses menggunakan smartphone, laptop, pc, dan device pintar lainnya. Protokol SNMP digunakan pada sistem ini untuk menerima informasi seperti resource server, jumlah paket yang diterima dan dikirim, informasi status, dan notifikasi yang berisi status dan waktu pada layanan server yang dipantau. Lingkup jaringan sistem yang dibangun mengadaptasi dari jaringan virtual yang kerap kali digunakan dalam melakukan pembangunan VPS (Virtual private server). Keunggulan dari sistem ini adalah mampu melakukan otomatisasi penghidupan layanan server menggunakan shell scripts sebagai basis perintah yang terdapat pada sistem operasi linux. Layanan server yang menjadi subjek dari fitur otomatisasi penghidupan antara lain adalah apache, mysql, dan ftp server.

\section{KAJIAN PUSTAKA}

Harrington, Presuhn, dan Wijnen (2002) memaparkan standar yang terdapat pada protokol SNMP. Standar tersebut meliputi konsep dan cara kerja SNMP yang digunakan setiap versinya. Nugroho, Afandi, dan Rahardjo (2014) melakukan perancangan aplikasi monitoring jaringan menggunakan protokol SNMP. Aplikasi monitoring yang dibangun bukan hanya melakukan monitoring jaringan saja, namun aplikasi dapat melakukan mapping terhadap jumlah device yang terdapat didalamnya. Selain itu, aplikasi ini juga dikembangkan untuk melakukan sistem peringatan dini terhadap perangkat jaringan yang dimonitoring. Taftazanie, Prasetijo, dan Widianto (2017) menjelaskan aplikasi pemantau jaringan berbasis web dengan menggunakan protokol SNMP dan notifikasi sms. SNMP digunakan untuk mengambil informasi dari perangkat pemantau jaringan dan notifikasi sms yang dibangun dikerjakan dengan protokol syslog. Liu dan Lu (2012) memaparkan aplikasi monitoring jaringan menggunakan protokol SNMP. SNMP digunakan untuk mengambil informasi $C P U$ usage rate, memory usage, dan traffic flow yang ada pada perangkat jaringan yang dipantau.

\section{METODOLOGI PENELITIAN}

Tahapan penelitian ini dilakukan secara berurutan yang terdiri dari sebagai berikut :

- observasi literatur

- Rancangan desain aplikasi \& topologi jaringan

- Instalasi sistem operasi server

- Implementasi arsitektur jaringan

- Instalasi \& konfigurasi software pendukung

- Implementasi sistem

- Pengujian sistem

- Kesimpulan
Pada tahapan observasi literatur dilakukan pencarian terhadap teori dan jurnal terkait dengan penelitian yang sedang dikerjakan. Hal ini diperlukan untuk menemukan dasar dari penelitian yang dikerjakan.

Selanjutnya memasuki tahapan perancangan desain aplikasi dan topologi jaringan untuk memberikan gambaran bentuk aplikasi yang akan dibangun serta kebutuhan jaringan sistem monitoring server.

Setelah menyusun desain topologi jaringan maka selanjutnya memasuki tahapan instalasi sistem operasi server. Pada tahapan ini perangkat virtual akan dipasang sistem operasi yakni Ubuntu 16.04 Desktop untuk manajer dan Ubuntu 16.04.5 Server untuk agent. Agent dan manager merupakan sebutan untuk membedakan deskripsi pekerjaan dalam menjalankan sistem montoring server. Definisi dari peran manager adalah melakukan pengambilan informasi dari data server yang dipantau, sedangkan definisi dari peran agent adalah melakukan pengiriman data informasi dari server yang dipantau ke server yang melakukan pemantauan (manajer). Di bawah ini merupakan spesifikasi komputer yang merupakan perangkat keras yang menampung semua resource perangkat virtual didalamnya.

Tabel 1. Spesifikasi Komputer

\begin{tabular}{lc}
\hline \multicolumn{1}{c}{ Komponen } & Jenis Perangkat \\
\hline Prosesor & Intel i5-7200U CPU @ 2.50GHz \\
RAM & $8 \mathrm{~GB}$ \\
HDD & $1 \mathrm{~TB}$ \\
\hline
\end{tabular}

Setelah server untuk manajer dan agen siap digunakan maka selanjutnya memasuki tahapan implementasi sistem jaringan. Pada tahapan ini, lingkungan jaringan yang dibangun akan mengadaptasi jaringan virtual sehingga memerlukan software pendukung untuk pembangunan sistem jaringan tersebut. Setelah implementasi jaringan selesai dikerjakan maka akan dilakukan pengujian konektivitas antar server dengan melakukan ping ke masing-masing server.
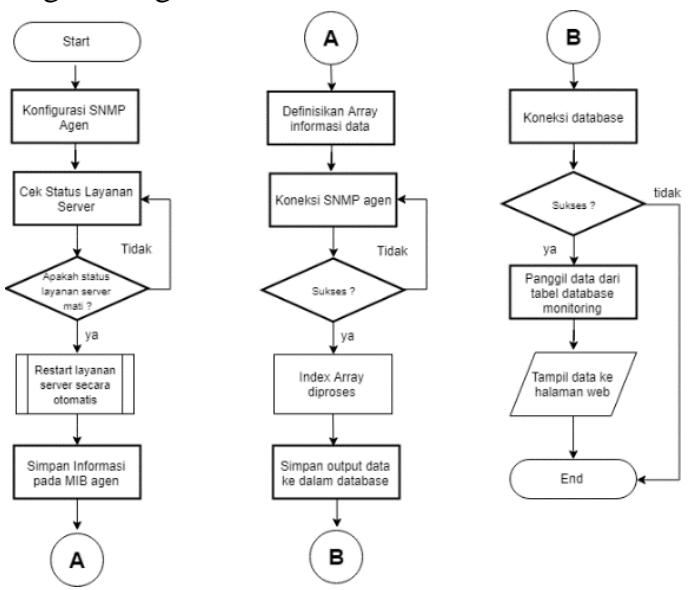

Gambar 1. Flowchart Sistem Monitoring Server 
Jika semua ping ke server yang akan dimonitor berhasil, maka selanjutnya memasukin tahapan instalasi software pendukung untuk menyiapkan sistem monitoring server. Software tersebut terdiri dari SNMP, Text Editor, Python, dan XAMPP yang akan digunakan dalam melakukan implementasi sistem monitoring server.

Setelah kebutuhan software pendukung terpenuhi maka selanjutnya memasukin tahapan implementasi sistem. Pada tahapan ini dibagi menjadi empat bagian yaitu sebagai berikut:

- Implementasi sistem pengambilan nilai SNMP

- Implementasi sistem penyimpanan nilai SNMP ke dalam database

- Implementasi sistem menampilkan data dari database

- Implementasi sistem notifikasi waktu dari status layanan server

- Implementasi sistem otomatisasi penghidupanan layanan server

Pada bagian implementasi pertama dilakukan dengan cara membuat program otomatisasi layanan server, hal ini dikarenakan SNMP akan melakukan pemanggilan data setiap menit untuk memproses informasi server yang dikonfigurasikan. Setelah proses pembuatan program otomatisasi layanan server dinyatakan berhasil maka selanjutnya memasuki tahapan implementasi proses definisi array. Pada tahapan ini dibuatlah sebuah program yang menyimpan sebuah array berisi index informasi server yang akan dieksekusi oleh SNMP. Setelah array dieksekusi dan data informasi yang dipanggil dapat disimpan pada database maka tahapan selanjutnya melakukan implementasi pemanggilan data yang telah disimpan pada database sebelumnya. Data yang telah dipanggil akan diproses kembali untuk ditampilankan pada halaman monitoring dan notifikasi di halaman web sistem monitoring server. Setelah keseluruhan proses implementasi dilakukan maka tahapan pengujian dilakukan untuk mengetahui tingkat keberhasilan dari sistem yang dibangun. Setelah hasil pengujian diketahui maka dibuatlah beberapa kesimpulan sebagai evaluasi yang dicapai dari penelitian ini.

\section{HASIL DAN PEMBAHASAN}

Pengujian sistem dilakukan untuk mengetahui fungsionalitas dari setiap fitur yang dibangun. Seperti yang disebutkan sebelumnya, pengujian dilakukan dengan menggunakan metode white box dan black box. Agar pengujian yang dilakukan memiliki dasar yang dapat diikuti pada penelitian ini maka di bawah ini merupakan gambar sebuah flowchart yang mempresentasikan cara kerja sistem yang seharusnya sebelum dilakukan pengujian.

Flowchart yang terdapat pada Gambar 1 dimulai dari pembuatan program otomatisasi penghidupan layanan server. Hal ini dikarenakan luaran dari program ini adalah informasi status layanan server yang datanya diambil setiap menitnya oleh SNMP.
Proses di atas berawal dari konfigurasi SNMP agen yang merupakan proses pengaturan SNMP pada perangkat server agen.

Setelah itu program melakukan pengecekan status layanan server seperti apache, mysql, dan ftp. Jika terdapat layanan server mati maka program melakukan restart secara otomatis pada layanan server yang mati tersebut dan informasi status layanan server disimpan pada MIB (Management Information Base) agent. Proses yang ditunjukan pada restart layanan server merupakan sub proses dari alur logika otomatisasi penghidupan layanan server. Sub proses restart layanan server ditunjukan pada Gambar 2.
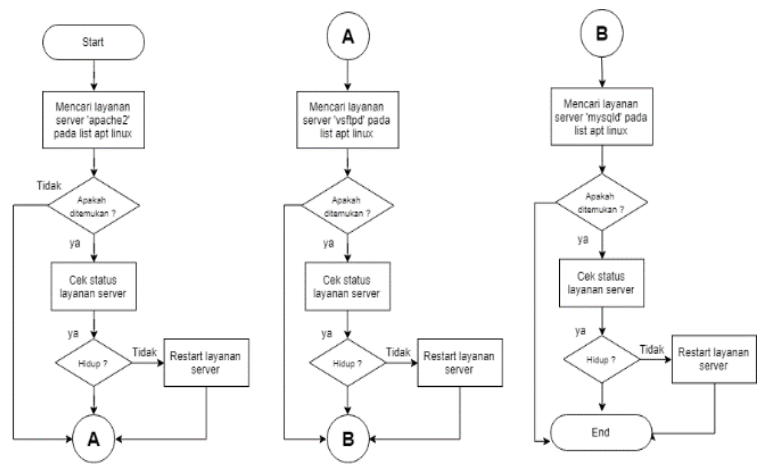

Gambar 2. Flowchart Proses Restart Layanan Server

Pada proses ini adalah akhir dari alur logika program otomatisasi penghidupan layanan server dan proses selanjutnya adalah alur logika program pengambilan informasi data monitoring dari SNMP agen. Program tersebut ditanam pada perangkat admin atau manajer sehingga diperlukan koneksi yang menghubungkan SNMP manajer dan SNMP agen.

Awal dari proses ini adalah melakukan definisi array yang berisi informasi data yang diperlukan untuk dipanggil dari SNMP agen. Selanjutnya program melakukan koneksi SNMP untuk menyesuaikan konfigurasi SNMP yang dilakukan pada alur proses pertama agar data yang didapatkan memang berasal dari perangkat server agen. Jika koneksi SNMP agen berhasil maka index array yang didefinisikan sebelumnya diproses dan hasil proses tersebut adalah melakukan pencocokan index array dengan nilai Object Identifier (OID) agar dapat memanggil data informasi yang berasal dari Management Information Base (MIB). Setelah data informasi didapatkan maka selanjutnya program melakukan penyimpanan data tersebut ke dalam database. Proses ini adalah akhir dari alur logika pemrograman pengambilan data monitoring server dan selanjutnya adalah proses alur logika dari pemrograman web sistem monitoring server.

Awal dari proses ini dimulai dari melakukan koneksi database dengan mendefinisikan user dan port yang digunakan oleh database. Jika koneksi database berhasil maka proses pemanggilan data dari database dapat dilakukan. Data dipanggil dan ditampilkan pada konten halaman web yang sudah diimplementasikan sebelumnya supaya data yang 
ditampilkan sudah siap disaji dalam bentuk yang lebih baik dan informatif. Hal ini merupakan proses akhir dari alur logika pemrograman web. Berdasarkan flowchart diatas berikut merupakan pengujian secara blackbox.

Tabel 2. Pengujian Blackbox

\begin{tabular}{|c|c|c|c|}
\hline No & $\begin{array}{l}\text { Skenario } \\
\text { Pengujian }\end{array}$ & $\begin{array}{l}\text { Hasil yang } \\
\text { diharapkan }\end{array}$ & $\begin{array}{l}\text { Kete- } \\
\text { rangan }\end{array}$ \\
\hline 1 & $\begin{array}{l}\text { Program dapat } \\
\text { melakukan } \\
\text { koneksi dengan } \\
\text { protokol } \\
\text { SNMP }\end{array}$ & $\begin{array}{l}\text { Program dapat } \\
\text { mengeksekusi } \\
\text { perintah pada } \\
\text { protokol SNMPv2 }\end{array}$ & $\sqrt{ }$ \\
\hline 2 & $\begin{array}{l}\text { Program dapat } \\
\text { mengambil } \\
\text { data monitoring }\end{array}$ & $\begin{array}{l}\text { Program berhasil } \\
\text { mengambil seluruh } \\
\text { data monitoring }\end{array}$ & $\sqrt{ }$ \\
\hline 3 & $\begin{array}{l}\text { Program dapat } \\
\text { melakukan } \\
\text { penyimpanan } \\
\text { data monitoring } \\
\text { ke dalam } \\
\text { database }\end{array}$ & $\begin{array}{l}\text { Program berhasil } \\
\text { menyimpan seluruh } \\
\text { data montoring ke } \\
\text { dalam database }\end{array}$ & $\sqrt{ }$ \\
\hline 4 & $\begin{array}{l}\text { Program dapat } \\
\text { menampilkan } \\
\text { data monitoring } \\
\text { yang terdapat } \\
\text { di database ke } \\
\text { dalam halaman } \\
\text { web }\end{array}$ & $\begin{array}{l}\text { Program berhasil } \\
\text { memanggil seluruh } \\
\text { data monitoring dari } \\
\text { database dan } \\
\text { menampilkan ke } \\
\text { dalam halaman web }\end{array}$ & $\sqrt{ }$ \\
\hline 5 & $\begin{array}{l}\text { Program dapat } \\
\text { menampilkan } \\
\text { notifikasi } \\
\text { waktu dari } \\
\text { status layanan } \\
\text { server }\end{array}$ & $\begin{array}{l}\text { Program berhasil } \\
\text { memperbaharui } \\
\text { informasi status } \\
\text { layanan server } \\
\text { dengan } \\
\text { menggunakan } \\
\text { waktu pada setiap } \\
\text { menitnya }\end{array}$ & $\sqrt{ }$ \\
\hline 6 & $\begin{array}{l}\text { Program dapat } \\
\text { melakukan } \\
\text { otomatisasi } \\
\text { penghidupan } \\
\text { layanan server } \\
\text { mysql, apache, } \\
\text { dan ftp server }\end{array}$ & $\begin{array}{l}\text { Program dapat } \\
\text { melakukan } \\
\text { otomatisasi } \\
\text { penghidupan } \\
\text { layanan server } \\
\text { mysql, apache, dan } \\
\text { ftp server }\end{array}$ & $\sqrt{ }$ \\
\hline
\end{tabular}

Gambar 3 dan Gambar 4 merupakan tampilan akhir dari sistem monitoring server.

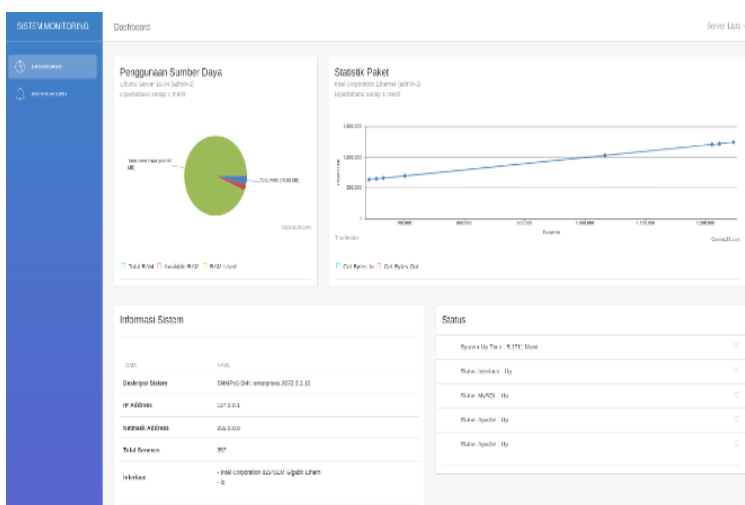

Gambar 3. Tampilan Halaman Utama Sistem Monitoring Server

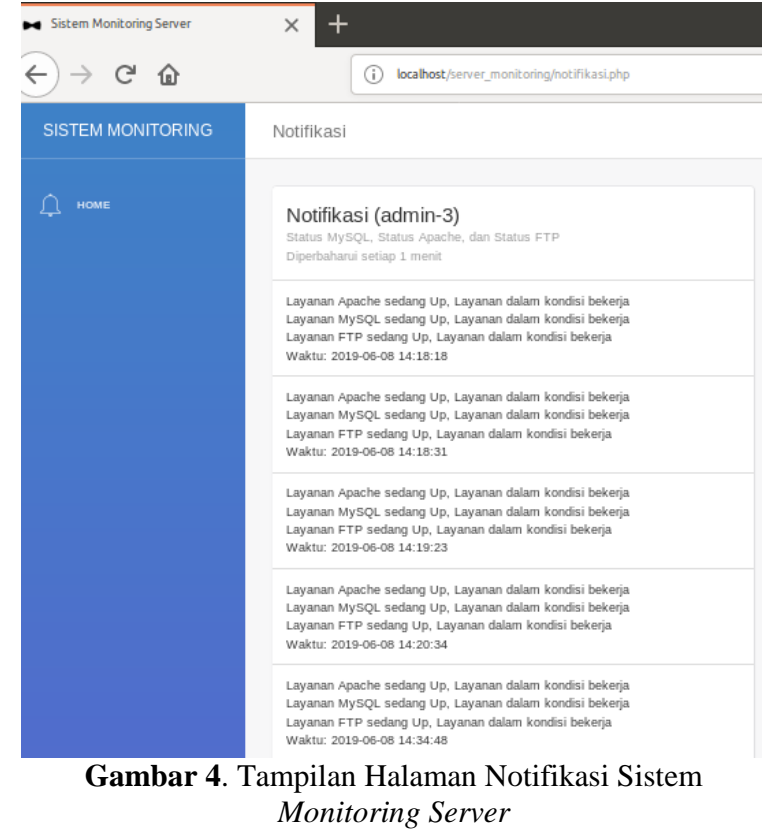

\section{KESIMPULAN}

Aplikasi sistem monitoring server berhasil memberikan informasi mengenai aktivitas server yang dipantau. Informasi seperti sistem server, resource, dan statistik paket sangat bermanfaat dalam memantau konektivitas jaringan server dan pemeliharaan memori server. Sistem otomatisasi juga bekerja dengan baik apabila terdapat layanan server yang mati secara tiba-tiba. Hal ini untuk mengurangi penghidupan secara manual.

\section{DAFTAR PUSTAKA}

Harrington, D., Presuhn, R. \& Wijnen, B., (2002). An architecture for describing simple network management protocol (SNMP) management frameworks (No. RFC 3411).

Nugroho, M., Affandi, A. \& Rahardjo, D. S., (2014). Rancang Bangun Aplikasi Monitoring Jaringan Menggunakan SNMP (Simple Network Management Protokol) dengan Sistem Peringatan Dini dan Mapping Jaringan. Jurnal Teknik Pomits, 3(1), 35-39. Taftazanie, S., Prasetijo, A. B. \& Widianto, E. D., (2017). Aplikasi Pemantau Perangkat Jaringan Berbasis Web Menggunakan Protokol SNMP dan Notifikasi SMS. Jurnal Teknologi dan Sistem Komputer, 5(2), 62-68.

Liu, R. J. \& Lu, R. (2012). Monitoring Network through SNMP-based System. International Journal of Intelligent Engineering and Systems, 5, 1-10. 